\title{
Characteristics of the dry/wet trend over arid central Asia over the past 100 years
}

\author{
Jinsong Wang ${ }^{1}$, Fahu Chen ${ }^{2}$, Liya Jin ${ }^{2, *}$, Huzhi Bai ${ }^{1}$ \\ ${ }^{1}$ Institute of Arid Meteorology, China Meteorological Administration, Key Open Laboratory of Arid Climatic Change and \\ Disaster Reduction, Key Laboratory of Arid Climatic Change and Reducing Disaster of Gansu Province, Lanzhou 730020, China \\ ${ }^{2}$ Center for Arid Environment and Paleoclimate Research, Key Laboratory of Western China's Environmental Systems, \\ Lanzhou University, Lanzhou 730000, China
}

\begin{abstract}
Stretching from the Caspian Sea in the west to the western part of northeast China in the east, arid central Asia is a transition belt between high latitude and low latitude areas. The arid climate of this geographic region has environmental effects far beyond its borders. In this study, the dry/wet trend in arid central Asia was examined over a temporal scale of $100 \mathrm{yr}$. Dry/wet change in an area is affected not only by precipitation, but also by temperature, because of its effect on potential evaporation. To more accurately describe the dry/wet trend, a drought index (DRI) was developed and calculated from gridded monthly air temperature and precipitation data from the Climate Research Unit, University of East Anglia, UK. Analysis of the DRI shows a general warm and dry trend for the region for the whole period between 1901 and 2002. A dry trend is seen in particular in the western part of Uzbekistan and Turkmenistan, central Kazakhstan, southern Xinjiang in China, and central Mongolia for the same period, while in northern Xinjiang, China, there was a weak wet trend. Over the past $100 \mathrm{yr}$, central Asia has experienced 6 wet-dry cycles: 1901-1910, 1911-1925, 1926-1935, 1936-1950, 1951-1960, and 1961-2002. The period and trend of the DRI are different from those of precipitation for the last $100 \mathrm{yr}$. The DRI can be used as an indicator of dry/wet change in arid central Asia because it reflects the concurrent effects of temperature and precipitation.
\end{abstract}

KEY WORDS: Arid central Asia $\cdot$ Drought index $\cdot$ Dry/wet trend

\section{INTRODUCTION}

Global warming is the most notable characteristic of climate change in the past $100 \mathrm{yr}$, and it has drawn widespread attention in both the scientific community and the general public (Jones \& Moberg 2003, Mann \& Jones 2003, Wang et al. 2005, Solomon et al. 2007). Hansen et al. (2002) used observational records and showed that global warming has been continuing as a consequence of increasing anthropogenic greenhouse gases in the atmosphere. The fourth assessment report of the IPCC (IPCC 2007) pointed out that the $100 \mathrm{yr}$ (1906-2005) linear trend of global surface temperature of $0.74 \pm 0.18^{\circ} \mathrm{C}$ is larger than the trend of $0.6 \pm 0.2^{\circ} \mathrm{C}$ for the $100 \mathrm{yr}$ from 1901 to 2000, given in the IPCC's third report. In addition, 3 representative time series of global temperature, CRUTEM2v (Jones \& Moberg
2003), NASA Goddard Institute for Space Studies (GISS, Hansen et al. 1999) and National Climatic Data Center (NCDC, Peterson et al. 1998), have also expressed temperature rise over the last $100 \mathrm{yr}$. The projections based on model simulations under different scenarios all indicate a further rise in surface temperature. An averaged warming rate of $0.2^{\circ} \mathrm{C}$ per decade has been projected for the $20 \mathrm{yr}$ period from 2006 to 2025, based on the IPCC Special Report on Emissions Scenarios (IPCC 2000), suggesting that global warming will continue in the future.

It is well known that rising temperature can result in increasing evaporation and decreasing soil moisture, favoring the occurrence of droughts. Precipitation and temperature records from 1900 to 1994 for 9 of the world's drylands (Hulme 1996) show that while warming was present in all sites, there was no consis- 
tent wet or dry trend in all those regions. Hulme's (1996) research also shows that the mean trends of precipitation in those drylands and the entire global land surface area are -11.1 and $30.6 \mathrm{~mm} 100 \mathrm{yr}^{-1}$, respectively. Chen et al. (1998) showed that precipitation has increased in the Yangtze River basin, Huaihe Valley, Hexi corridor, and the southern part of China (shown in Fig. 1). They also showed that along with the increase in precipitation, warming temperature has resulted in glacial melting, increasing runoff, and rising lake levels and lake areas. The area in the Tianshan Mountains in northwest China (shown in Fig. 1) has shown a strong climate-change signal from a warm-dry to warm-wet climate since 1987 (Shi et al. 2003). An increased intensity and frequency of extreme rainfall was also seen in Xinjiang Province, China (shown in Fig. 1) (Yang 2003). Although the precipitation has increased in these areas, it is still unclear whether this increase can compensate for the increase in evaporation induced by increasing air temperature. Because the variation of wetness/dryness is caused by a change in water balance, studies on the wet/dry trend must consider precipitation and evaporation simultaneously.

Arid central Asia, which is located in the inland of middle-latitude Asia (Fig. 1), has also shown a clear increase in air temperature in association with global warming. The rate of increase of the annual mean temperature in arid central Asia is $0.18^{\circ} \mathrm{C}$ per decade for the last $100 \mathrm{yr}$ (Chen et al. 2009). The change in temperature in this region is of a greater magnitude than in other regions in China and is approximately twice the rate of temperature increase in the Northern Hemisphere $\left(0.074^{\circ} \mathrm{C}\right.$ per decade) (Jones \& Moberg 2003).
Tree ring records from Mongolia and the Tianshan Mountains suggest that temperature has been increasing continuously throughout the 20th century in central Asia (Jacoby et al. 1996, Esper et al. 2003). A related question is how precipitation in central Asia has changed in association with the region's temperature increase and global warming. Additionally, how might these temperature and precipitation changes have resulted in a persistent dry/wet trend in the region?

Northern China, as the main part of arid central Asia, is also facing a series of environmental problems related to global change. Studies have indicated that a drought trend is one of the most serious problems in northern China, and global warming and human activities have a key impact on it (Fu \& An 2002, Fu et al. 2005). In order to reduce the impacts of drought and improve environmental conditions, some researchers have constructed simulation models to study aridification (Ren et al. 2002, Tao et al. 2003, Shi et al. 2004). These studies show that an increase in the amount of water taken from rivers, a decrease in precipitation, and an increase in soil-moisture deficit are the future environmental challenges in northern China. Proposed solutions include adjusting land-use patterns based on the integration of hydrological, soil erosion, and landuse models. However, using advanced irrigation technology, increasing the application of high-efficiency water use, and improving regional water resources capacity in northern China will also be necessary.

In the present study, a drought index (DRI), which is a function of both precipitation and evaporation, was defined and used to analyze the characteristics of the dry/wet trend of the past $100 \mathrm{yr}$ in arid central Asia.

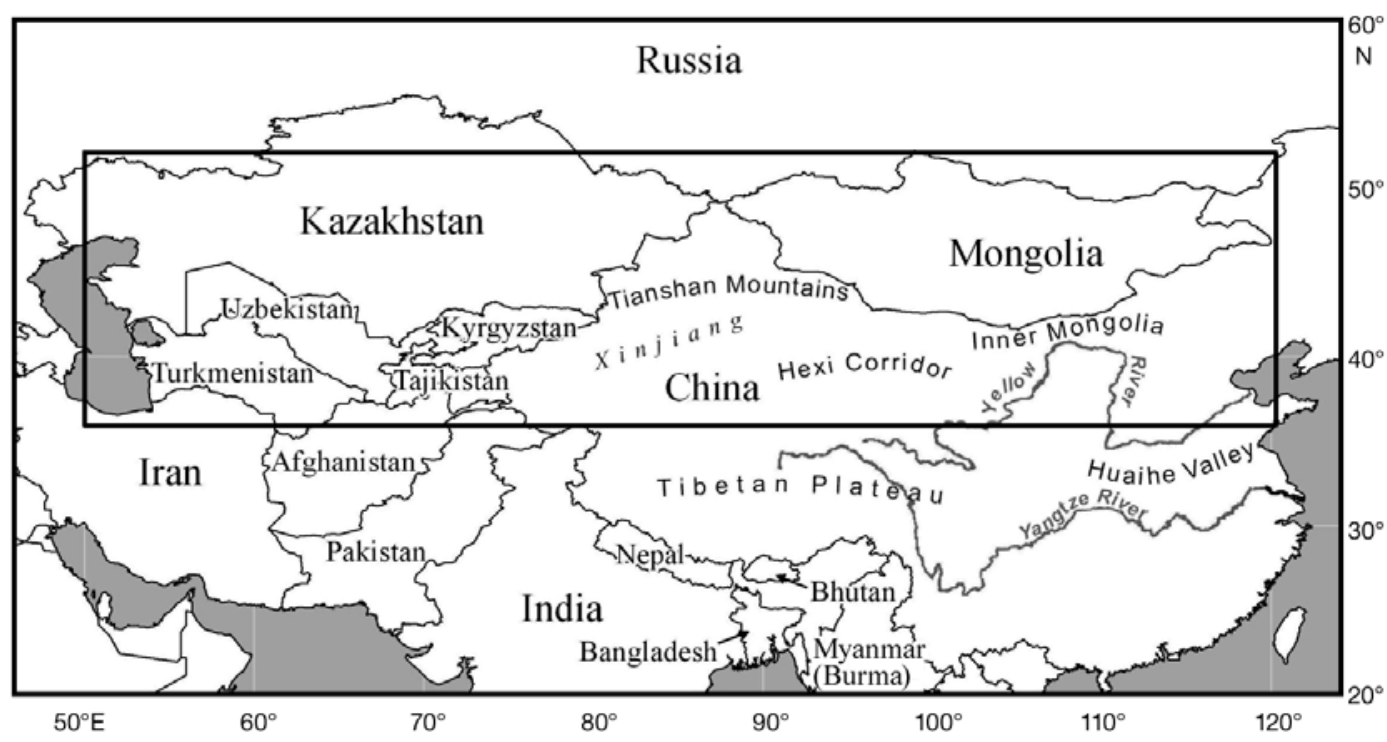

Fig. 1. Arid central Asia (black rectangle) 


\section{METHODS}

2.1. Data. We used high-resolution gridded $(0.5 \times$ $0.5^{\circ}$ ) annual mean precipitation and surface air temperature data obtained from the Climate Research Unit (CRU) and the Tyndall Center of the University of East Anglia (CRU TS 2.1; www.cru.uea.ac.uk). The data period is from 1901 to 2002.

2.2. Trend coefficient and variability. The trend coefficient and variability can be used to denote the quality and magnitude of changes of a meteorological factor (Wei 1999). The trend coefficient is calculated from:

$$
r_{x t}=\frac{\sum_{i=1}^{n}\left(x_{i}-\bar{x}\right)(i-\bar{t})}{\sqrt{\sum_{i=1}^{n}\left(x_{i}-\bar{x}\right)^{2} \sum_{i=1}^{n}(i-\bar{t})^{2}}}
$$

where $r_{x t}$ is the trend coefficient, $n$ is the length of the temporal series (i.e. number of years), $x_{i}$ is the value of any climate factor in year $i, \bar{X}$ is the mean value of the samples, and $\bar{t}=(n+1) / 2$.

The climatic variability is a linear regression coefficient between the climatic factor and time, and is estimated using the least square method. It has the form:

$$
k=\frac{\sum_{i=1}^{n}\left(x_{i} t_{i}\right)-\frac{1}{n}\left(\sum_{i=1}^{n} x_{i}\right)\left(\sum_{i=1}^{n} t_{i}\right)}{\sum_{i=1}^{n} t_{i}^{2}-\frac{1}{n}\left(\sum_{i=1}^{n} t_{i}\right)^{2}}
$$

where $k$ is the climatic variability (temperature, ${ }^{\circ} \mathrm{C} \mathrm{yr}^{-1}$ ), $t_{i}$ is the corresponding time for $x_{i}$, and $n$ is the quantity of samples (i.e. number of years).

2.3. Mann-Kendall method. The Mann-Kendall method was used to evaluate the trend of precipitation and DRI. The Mann-Kendall method is one of the most widely applied tests to detect the trend and abrupt change of a climate variable (Sneyers 1990). A positive (negative) value of the Mann-Kendall test indicates an increasing (decreasing) trend.

2.4. Singular spectrum analysis. Singular spectrum analysis (SSA) is a statistical method that has often been used to identify secular variations (e.g. linear trends and/or oscillations) of a time series. It is a generalized power spectrum analysis, and does not assume sinusoidal functions for the variation components. Another major advantage of the SSA compared to other spectral analysis methods (e.g. maximum entropy spectral analysis) is that SSA does not require that a spectral filter be specified in advance. Instead, a filter is determined internally by capturing variations contained in the data being analyzed. By detecting a wide range of variation signals in the data, including longterm trends, this filter allows examination of both trends and oscillations of a climate data series (Jiang \&
Ding 1998, Wei 1999). The computational steps of the SSA are detailed in Wu \& Duan (1998).

2.5. Rotated empirical orthogonal function. Rotated empirical orthogonal function (REOF) analysis has been widely used in statistical studies in meteorology (Servain \& Legler 1986, Kawamura 1994, Huang 1998, Tu et al. 2000). Its major advantage compared to the standard empirical orthogonal function (EOF) is that it can more accurately describe regional characteristics of meteorological fields by rotating the expansion coordinates. In the present study, REOF analysis was used to investigate spatial features in temperature variations in different subregions.

\section{DROUGHT INDEX}

A drought index can be used to describe the intensity of drought in an area. Wang (1990) pointed out that drought indices may be defined differently depending on how water efflux is expressed, especially evaporation. Examples of drought indices include the Palmer Drought Severity Index (Palmer 1965), Standardized Precipitation Index (McKee et al. 1993), Crop Moisture Index (Palmer 1968), and Surface Water Supply Index (Shafer \& Dezman 1982).

We define the drought index DRI as:

$$
\mathrm{DRI}=E-P
$$

where $E$ is potential evaporation and $P$ is precipitation, and these can be annual or monthly mean values. A positive DRI value indicates drought. In the present study, $P$ is the annual precipitation and $E$ is the annual potential evaporation. Thus annual dry/wet characteristics are described by DRI. The annual precipitation data were obtained from the CRU (www.cru.uea.ac.uk). Monthly potential evaporation was calculated with a modified Thornthwaite method (Thornthwaite 1948) and converted to annual potential evaporation.

It should be noted that potential evaporation is different from meteorological measurements using evaporation pans. Pan evaporation measured with a 20 or $70 \mathrm{~cm}$ pan at a meteorological station is an overestimate of evaporation of large areas (Fu 2001). Many methods have been developed to estimate potential evaporation; all of them have limitations. Currently, widely used methods include Penman's energy balance and Thornthwaite's empirical method. Although Thornthwaite's method has limitations, it is widely used by meteorologists and plant ecologists to evaluate climate type and vegetation relationship, and to estimate irrigation needs in agriculture (Zhang 1989, Ci 1994). The Thornthwaite method has been used in calculations of the Palmer Drought Severity Index (Palmer 1965), potential evaporation, and climate classification 
by the United Nations. This method has also been used to study dry/wet changes of northern China (Ma et al. 2005), justifying its use in the present study.

The modified Thornthwaite equation for monthly evaporation $E_{\mathrm{m}}$ is:

$$
E_{m}=\left\{\begin{array}{cc}
0 & T_{i} \leq 0^{\circ} \mathrm{C} \\
16 d\left(10 T_{i} / I\right)^{a} & 0^{\circ} \mathrm{C}<T_{i} \leq 26.5^{\circ} \mathrm{C} \\
a_{1}+a_{2} T_{i}+a T_{i}^{2} & T_{i}>26.5^{\circ} \mathrm{C}
\end{array}\right.
$$

where $d$ is the number of days in a month divided by 30 (for $12 \mathrm{mo}$ ), $T_{i}$ is the mean temperature of month $i\left({ }^{\circ} \mathrm{C}\right)$, and $a$ is a function of heating index $I$, expressed as:

$a=0.000000675 I^{3}-0.0000771 I^{2}+0.01792 I+0.49239$

$I=\sum_{1}^{12} i$ is the sum of monthly heating indices, and $i=\left(\mathrm{T}_{i} / 5\right)^{1.514}$ is the monthly heating index. In Eq. (4), $a_{1}=-415.8547, a_{2}=32.2441$, and $a_{3}=-0.4325$. Annual potential evaporation is given as: $E=\sum_{1}^{12} E_{m}$.

\section{DRY/WET TREND OVER THE PAST 100 YEARS}

The study area was located between 36 to $52^{\circ} \mathrm{N}$ and 50 to $120^{\circ} \mathrm{E}$, which includes the arid and semiarid regions of central Asia, encompassing Mongolia, northwestern China, and Inner Mongolia of China (Fig. 1). This area is influenced by complex atmospheric circulations, as the boundary of the westerly jet migrates north and retreats south during the summer and winter months, respectively. The study area is mostly influenced by westerlies with the eastern part also influenced by Asian monsoon circulation. A study on central Asian Holocene moisture evolution from proxy data have shown that the effective-moisture history in central Asia was out of phase with that in monsoonal Asia (Chen et al. 2008). In other words, a wet monsoon in Asia corresponded to a dry arid central Asia during the early Holocene, and a decreased monsoon coexisted with a wet central Asia during the mid- and late Holocene. In the present study, the detection of a dry/wet trend over the last $100 \mathrm{yr}$ in arid central Asia was also compared with the dry/wet trend in the east Asian monsoon area.

The DRI between 1901 and 2002 was analyzed to reveal the trend of dry/wet changes. In order to better understand the regional character of the dry/wet trend, we used the REOF method to divide the study area into several subregions. The first 5 loading vectors of the EOF expansion (explaining $85 \%$ of the total variance) were subjected to an REOF expansion. After rotation, the accumulated percent variance of the first 4 rotated loading vectors exceeded $80 \%$ of the total variance, which is useful in describing the regional features of the variations. By taking 0.6 as a threshold value for the rotated loading vectors in the REOF (Fig. 2), we divided the entire region into 4 subregions (Fig. 3), i.e. the arid area of central Asia (Subregion I), arid area of the Mongolian Plateau (Subregion II), Tarim arid area (Subregion III), and the East Asian monsoon area (Subregion IV).

The trend coefficient and variability of the DRI, precipitation, and temperature series for the last $100 \mathrm{yr}$ were calculated by using Eqs. (1) and (2). On a $100 \mathrm{yr}$ scale, if the absolute test value was $>0.2$ and the confidence level was $>95 \%$, the trend was recognized as statistically significant. The secular trends for mean precipitation and DRI in each of the 4 subregions were calculated using the Mann-Kendall method (threshold value of 1.96 at $\alpha=0.05$ )

Fig. 4 shows the distribution of the trend coefficient for temperature, precipitation, and DRI in the study areas. Nearly all subregions (except for a small part in Subregion IV) showed an increase in temperature
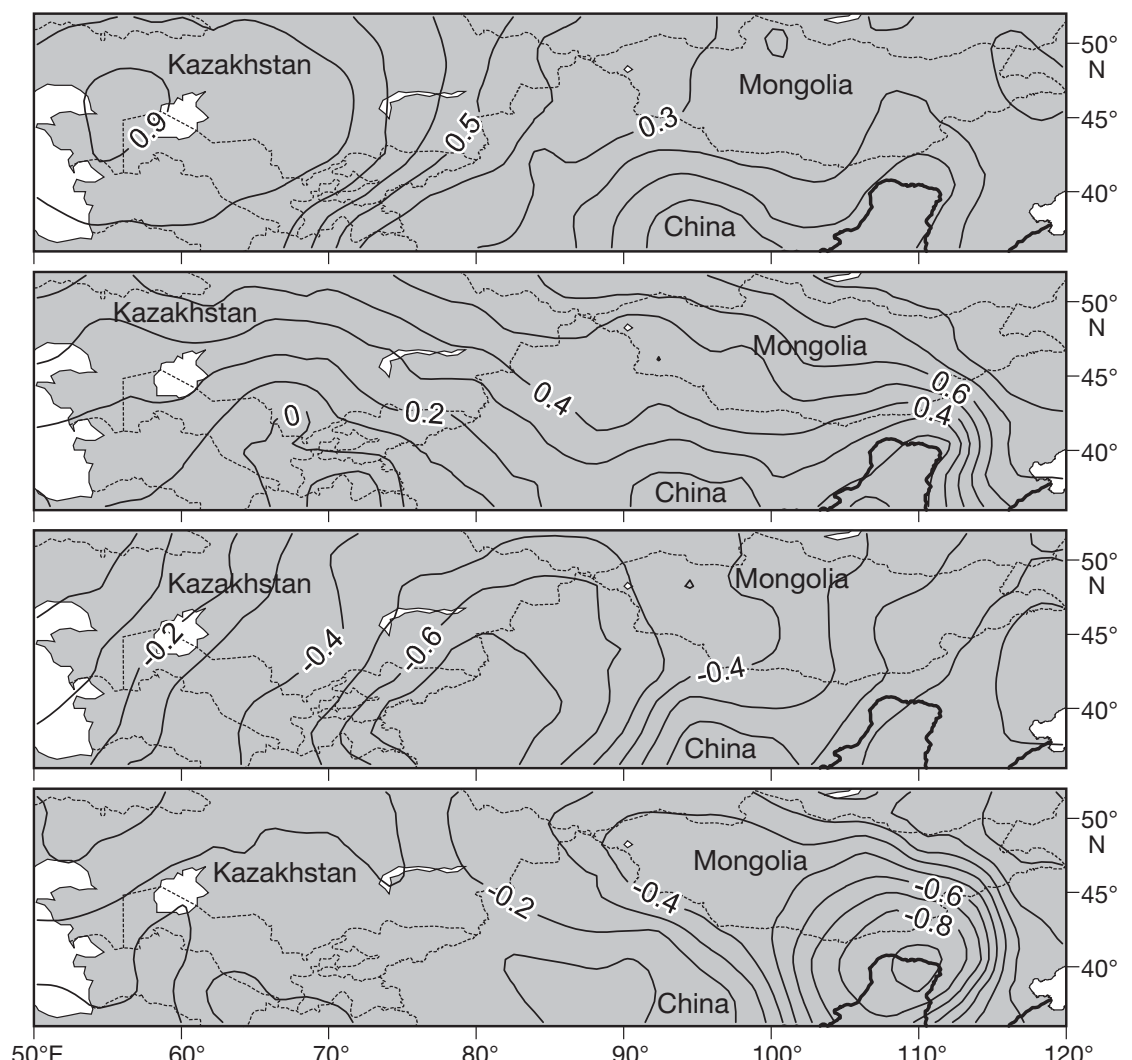

Fig. 2. Distribution of the first 4 rotated loading vectors in arid central Asia 


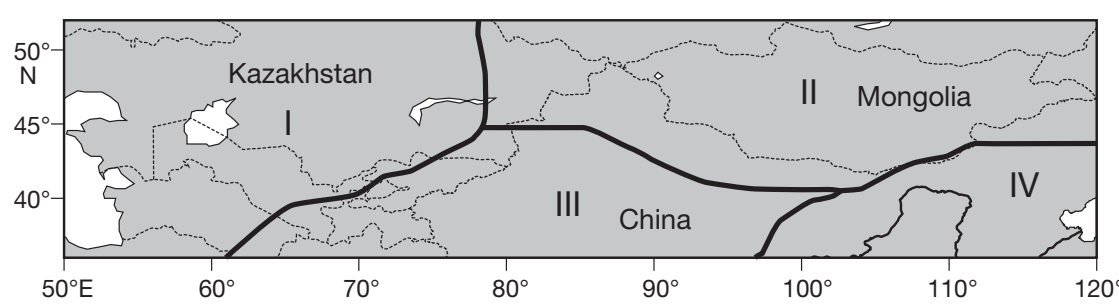

Fig. 3. The 4 subregions in arid central Asia. Subregion I: arid area of central Asia; Subregion II: arid area of the Mongolian Plateau; Subregion III: Tarim arid area; and Subregion IV: East Asian monsoon area
A significant increase in precipitation for the last $100 \mathrm{yr}$ was seen in northern Xinjiang (western Subregions II and III), west Kazakhstan (western Subregion I), and Turkmenistan, Uzbekistan, Kyrgyzstan, and Tajikistan (southern Subregion I). Only a small area in central Kazakhstan showed a significant decrease in precipitation (Fig. 4b).

Although the increasing precipitation may suggest a trend of wetter conditions in these areas, the simultaneous

(Fig. 4a). The most significant increase was in the Xinjiang Province of China (western Subregions II and III) and adjacent middle and southern Mongolia (Subregion II). Another significant increase in temperature was seen in Lake Balkhash (east Kazakhzstan) and its surrounding areas. In these regions, the trend coefficient of annual mean temperature exceeded 0.2 , with a confidence level of $\alpha=0.05$. The southern Xinjiang basin and central Mongolia appear to have the greatest increase in temperature, with a trend coefficient $>0.6$, at confidence level of $\alpha=0.001$.
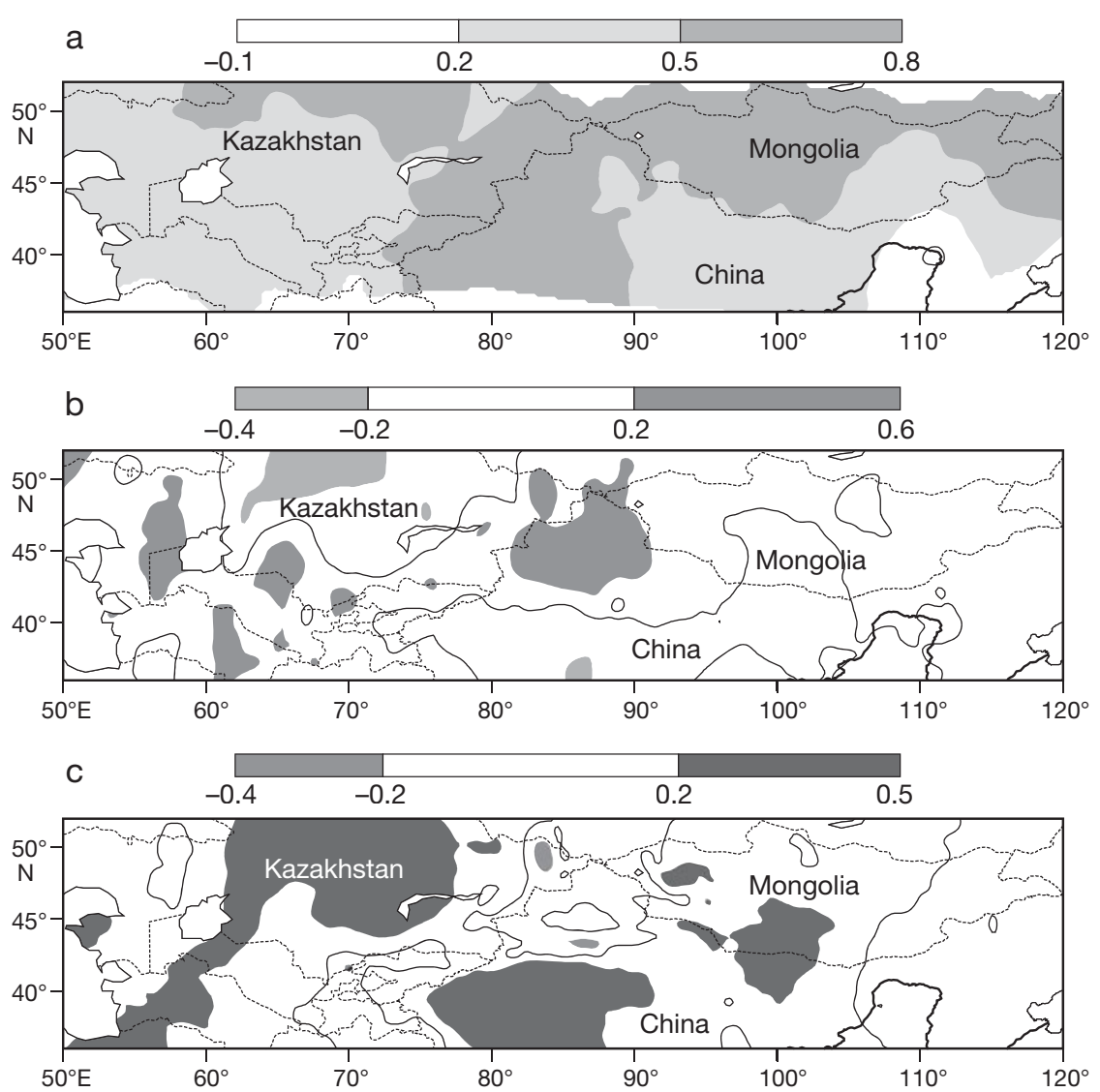

Fig. 4. Distribution of the trend of annual (a) temperature, (b) precipitation, and (c) drought index (DRI) in arid central Asia from 1901 to 2002. Areas where trends are significant (at a level of $\mathrm{p}<0.05$ ) are shaded increase in temperature would result in increasing potential evaporation, countering the precipitation effect. The combined effect of these changes on the environment can be described by the DRI. The computed DRI is shown in Fig. 4c. The combined temperature and precipitation changes resulted in significant dry conditions in Uzbekistan, west Turkmenistan, central Kazakhstan, southern Xinjiang basin, and the middle border between China and Mongolia. These are also the areas where annual temperature has increased significantly (Fig. 4a) in the last 100 yr. Although the annual precipitation significantly increased in northern Xinjiang and west Kazakhstan (Fig. 4b), the increased precipitation was apparently not enough to compensate for the effect of increasing evaporation due to rising temperatures. Therefore, only a mild wet condition was seen in northern Xinjiang.

To check the dry/wet trend for the past $100 \mathrm{yr}$, the Mann-Kendall method was used for annual precipitation and DRI for each subregion (Fig. 5). For the Mann-Kendall trend test of the DRI, a positive value represents dry conditions, and a negative value represents wet conditions. Fig. 5a shows a trend of increasing DRI (positive Mann-Kendall coefficient of DRI) in the arid area of central Asia (Subregion I) during the past $100 \mathrm{yr}$ and a trend of increasing precipitation from the early 1950s to the present. The arid area of the Mongolian Plateau (Subregion II, Fig. 5b) experienced a significant trend of increasing annual precipitation after 1950, coexisting with a weak dry trend (negative DRI). The Tarim subregion (III) showed a slightly enhanced trend of dryness (Fig. 5c). Because the warming trend was prominent and the increase in precipitation was insufficient to compen- 

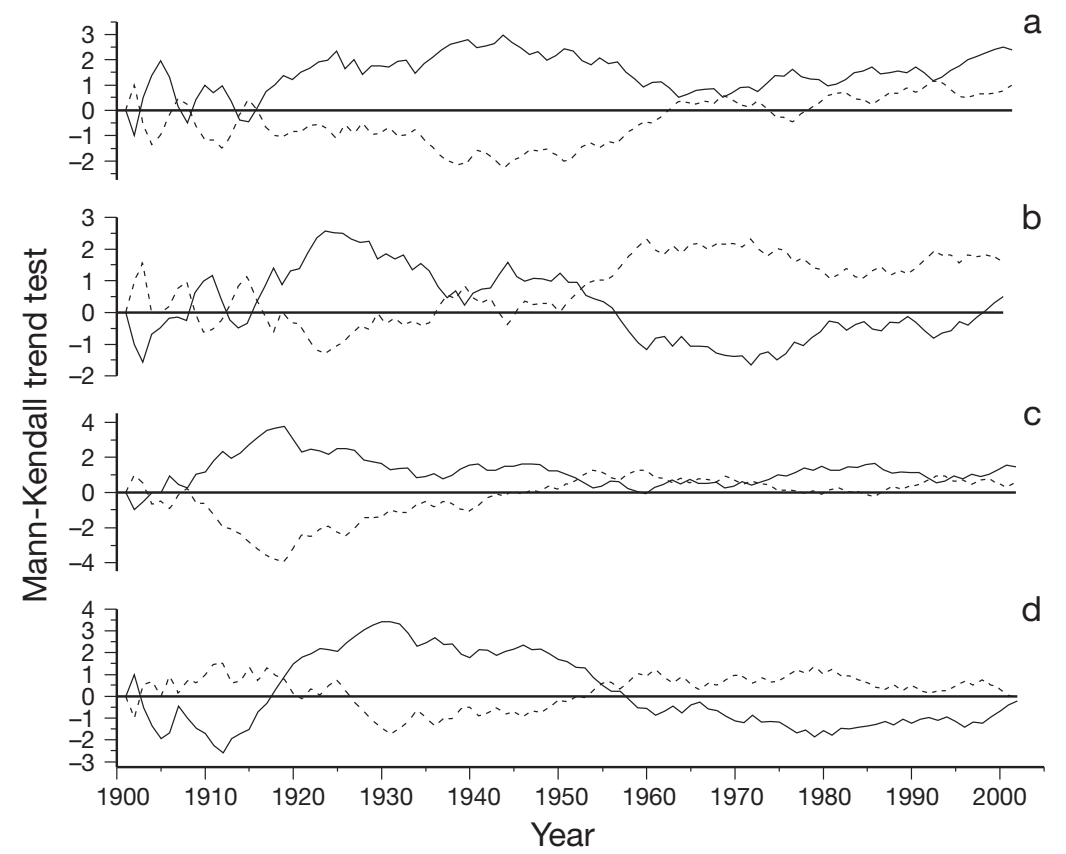

Fig. 5. Trend of mean precipitation and drought index (DRI) in (a) Subregion I, (b) Subregion II, (c) Subregion III, and (d) Subregion IV. See Fig. 3 for subregion locations. (-) trend in DRI; (- - ) trend in precipitation subregion (IV) showed the smallest increase. The arid area of central Asia (Subregion I) showed the largest increase in DRI (27.57 $\mathrm{mm} 100 \mathrm{yr}^{-1}$ ). The Tarim region (Subregion III) also showed a significant drying trend. A weak drying trend is shown in the Mongolian region (Subregion II). In contrast, the East Asian monsoon subregion (IV) exhibited a wet trend, with a decrease in DRI (-2.39 mm $\left.100 \mathrm{yr}^{-1}\right)$, even though the region's precipitation increased slightly over the century (2.84 mm $\left.100 \mathrm{yr}^{-1}\right)$. A similar wet trend is also apparent in the East Asian monsoon subregion, with a decrease in DRI (-2.39 mm $\left.100 \mathrm{yr}^{-1}\right)$, even though the region's precipitation increased slightly over the century (2.84 mm $100 \mathrm{yr}^{-1}$ ). This difference between the trends in DRI and precipitation may be an indication of the strong causative role that increasing temperature plays in the developing dry conditions in these areas. sate for the increasing evaporation, the Tarim subregion still shows a trend of drying. The East Asian monsoon area showed a unique characteristic of climate fluctuation with the DRI in this subregion (IV), decreasing substantially (Fig. 5d) as a result of lower temperatures that reduced potential evaporation; this subregion also exhibited a small increase in precipitation. Linear variation rates of annual temperature, annual precipitation, and DRI for the 4 subregions are summarized in Table 1.

All 4 subregions exhibited a trend of increasing annual mean temperature, with the maximum rate at $1.56^{\circ} \mathrm{C} 100 \mathrm{yr}^{-1}$ in Subregion II (Table 1). Annual precipitation also appears to be increasing. The subregion in Mongolia showed the largest increase in precipitation (14.16 mm $100 \mathrm{yr}^{-1}$ ), while the East Asian monsoon

Table 1 . Trend variability of temperature $(T)$, precipitation $(\mathrm{P})$, and drought index (DRI) in the arid area of central Asia (Subregion I), arid area of the Mongolian Plateau (Subregion II), Tarim arid area (Subregion III), and East Asian monsoon area (Subregion IV). See Fig. 3 for subregion locations. ${ }^{*} p<0.05$; ${ }^{* *} \mathrm{p}<0.01 ;{ }^{* * *} \mathrm{p}<0.001$

\begin{tabular}{|lccc|}
\hline Subregion & $\begin{array}{c}T \\
\left({ }^{\circ} \mathrm{C} 100 \mathrm{yr}^{-1}\right)\end{array}$ & $\begin{array}{c}\mathrm{P} \\
\left(\mathrm{mm} \mathrm{100} \mathrm{yr}^{-1}\right)\end{array}$ & $\begin{array}{c}\mathrm{DRI} \\
\left(\mathrm{mm} \mathrm{100} \mathrm{yr}^{-1}\right)\end{array}$ \\
\hline I & $1.45^{* * *}$ & 9.83 & $27.57^{*}$ \\
II & $1.56^{* * *}$ & $14.16^{*}$ & 5.65 \\
III & $1.23^{* * *}$ & 11.36 & 15.32 \\
IV & $0.62^{* *}$ & 2.84 & -2.39 \\
\hline
\end{tabular}

\section{DRI VARIATIONS OVER THE PAST 100 YR}

To understand the dry/wet trend in arid central Asia, DRI variations were further examined using SSA. The band width of the filter in the SSA was determined to be 30 by the SSA scheme. The spectral/reconstruction components (RCs) of the SSA were tested by Kendall non-parametric tests. For comparison purposes, SSA was also applied to temperature and precipitation in arid central Asia.

Fig. 6 shows the SSA reconstruction for the annual mean temperature in arid central Asia, and a clear rising trend in annual temperature can be seen (Fig. 6a). Before 1970, the annual mean temperature fluctuated on a slightly rising trend. After 1970, it rose steadily. At higher modes of the variations in temperature, the variations with $21.05,8.85$, and 3.97 yr cycles dominated. Interestingly, the 21.05 yr cycle has a nearly unchanged amplitude (Fig. 6b), while the 8.85 and $3.97 \mathrm{yr}$ cycles (Fig. 6c,d) have varying amplitude.

The trend component of the annual precipitation from the SSA reconstruction for all of central Asia showed a slight decrease in the first $10 \mathrm{yr}$ of the 20th century (Fig. 7a), and a significant increase from the 1910 s to the 1950s. This component reached its maximum in the early 1960s, followed by a gradual decrease in recent years. In the reconstruction's high modes, the 6 yr cycle appears to be obscure in the 
1970s (Fig. 7b). In contrast, the 3 yr cycle seems to be rather robust (Fig. $7 \mathrm{c}$ ).

The DRI trend and higher frequency variations for all of arid central Asia from the SSA reconstruction are

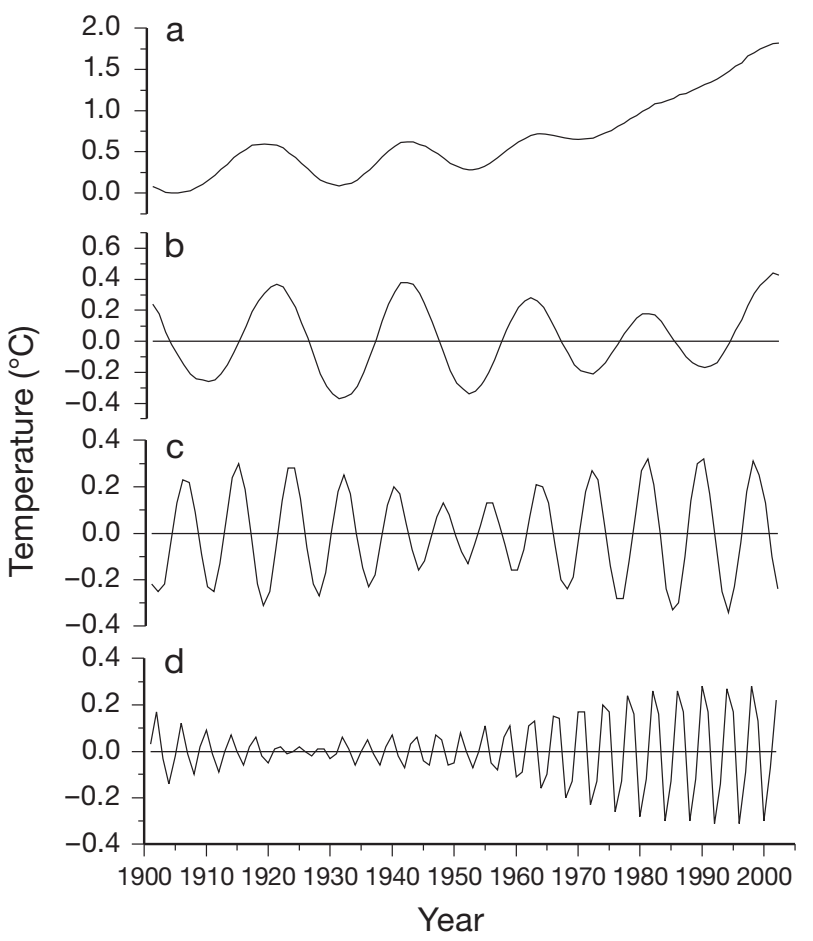

Fig. 6. Singular spectrum analysis-based reconstruction components (RCs) of annual mean temperature in arid central Asia. (a) RC1 + RC2: trend component; (b) RC3 + RC4: 21.05 yr cycle; (c) RC5 + RC6: 8.85 yr cycle; and (d) RC11 + RC12: 3.97 yr cycle

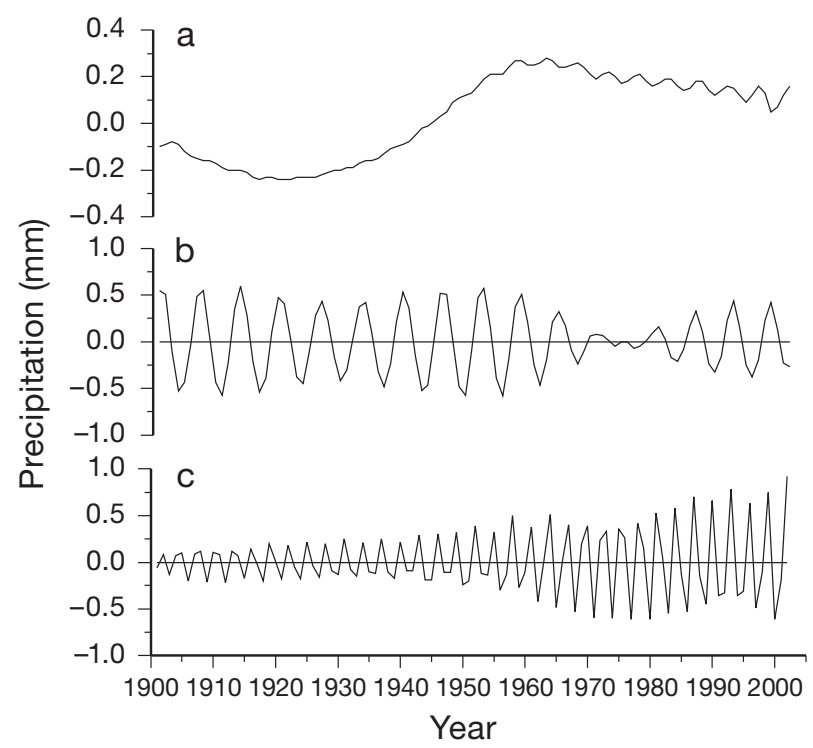

Fig. 7. Singular spectrum analysis-based reconstruction components (RCs) of annual precipitation in arid central Asia. (a) RC7: trend component; (b) RC1 + RC2: 6.25 yr cycle and (c) RC3 + RC4: 2.92 yr cycle shown in Fig. 8. These results show that the DRI varied from a rising trend before 1940 to negative values from the end of the 1940s to the 1950s, indicating a dry trend before 1940 developing into a wet trend in the 1950s. It can also be seen that the first 10 yr of the 20th century and the years from the mid-1920s to the mid-1930s were relatively wet. A transition from wet to dry conditions occurred in the early 1960s, and a dry trend has continued in recent years (Fig. 8a).

All the higher frequency variations show varying amplitudes in the study period. Among these variations, the 10.47 yr cycle has relatively small fluctuations in its amplitude (Fig. 8d). Since 1960, the $2.9 \mathrm{yr}$ cycle began to amplify (Fig. 8b). The 5.8 yr cycle shows some internal variations in its amplitude (Fig. 8c).

To summarize, the variations in the DRI described by the major components from the SSA analysis show 6 wet-dry phases occurring alternately in arid central Asia over the past $100 \mathrm{yr}$ (Fig. 9). The first $10 \mathrm{yr}$ of the 20th century were relatively wet, followed by a dry period during the 1910s to mid-1920s. This dry period was replaced by another wet period from the mid1920 s to the mid-1930s. Another dry period emerged and lasted from the mid-1930s to 1950. After a transition in the 1950s, a dry period began in the early 1960s and lasted until recent years.
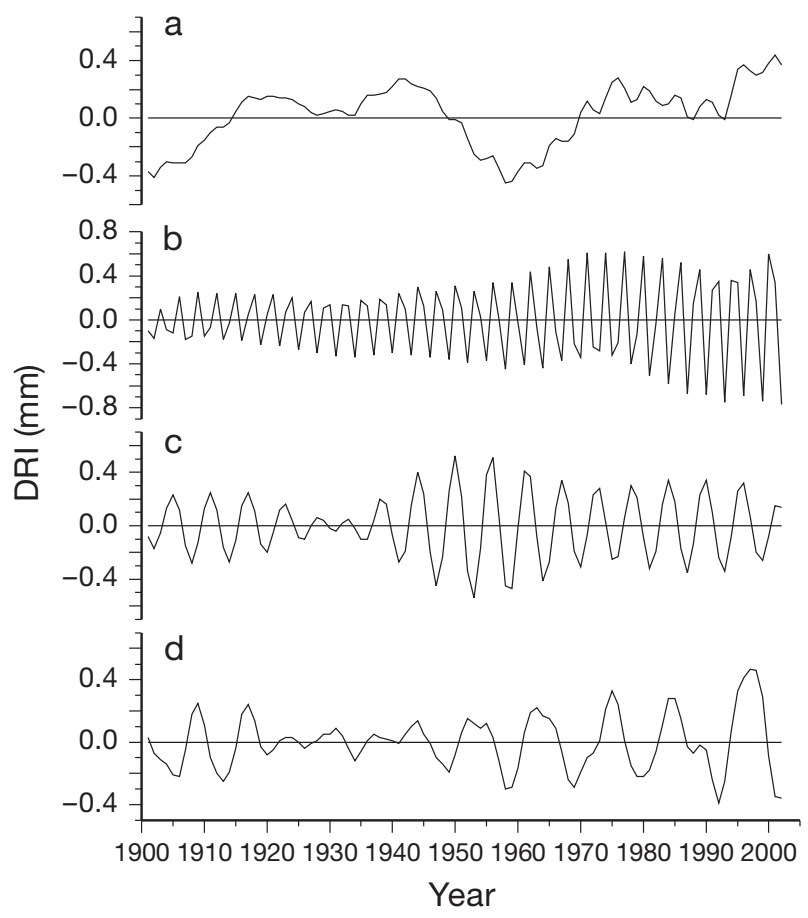

Fig. 8. Singular spectrum analysis-based reconstruction components (RCs) of drought index (DRI) in arid central Asia. (a) RC1 + RC9: trend component; (b) RC2 + RC3: 2.93 yr cycle; (c) RC5 + RC6: 5.81 yr cycle; and (d) RC11 + RC12: 10.47 yr cycle 


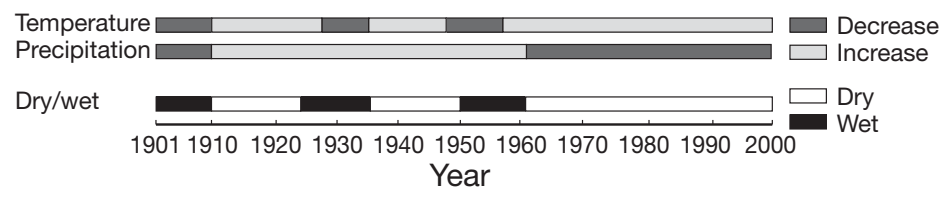

Fig. 9. Evolution of temperature, precipitation, and the dry/wet trend in arid central Asia

\section{CONCLUSIONS}

In the past $100 \mathrm{yr}$, the climate in arid central Asia has been dominated by a warming and drying trend. Superimposed on this trend were wet periods from 1901 to 1910 , the mid-1920s to the mid-1930s, and 1950 to 1960 . Some regions and/or areas showed a clear increase in precipitation corresponding with mild increasing wetness, such as in the northern Xinjiang Province of China; other areas with increased precipitation did not show a corresponding increase in wetness. Instead, a trend of dryness was observed in those areas, such as Turkmenistan, Uzbekistan, Kyrgyzstan, Tajikistan, and west Kazakhstan. Obviously the effect of temperature change must have played a more important role in the dry trend in those areas. In the regions of reduced precipitation and warming (e.g. central Kazakhstan, the southern Xinjiang basin of China, and central Mongolia), the drying trend strengthened considerably.

During the past $100 \mathrm{yr}$, the variation in the annual mean temperature averaged over all of central Asia has been dominated by a 21 yr cycle and, to a lesser degree, a 9 yr cycle, while the annual precipitation variation exhibits 3 and 6 yr cycles. The variations in DRI are dominated by 3 and 11 yr cycles.

Based on analysis of the DRI, it can be concluded that the combined effect of precipitation and temperature anomalies determines the dry/wet trend in an area, such as in arid central Asia. Because global warming is likely to continue into the future (IPCC 2007), temperature effects will continue to influence precipitation anomalies and strongly affect the wet/dry trend of regional climate. Our results also indicate that there is no evidence that the current drying trend in arid central Asia will diminish soon. Extension of the warm/dry conditions is likely to result in certain environmental and socioeconomic problems, such as water shortage. It is important to develop mitigation plans to reduce the impacts of drying trends on societies and the environment.

Acknowledgements. This study was supported by the National Natural Science Foundation of China (grant no. 40875046), the Ten Talents Project of Gansu Provincial Meteorological Bureau, the National Natural Science Foundation of China Innovation Team Project (grant no. 40721061), and the Ministry of Education 111 project (grant no. B06026). The authors thank the editor of this paper and the 2 anonymous reviewers. We also express our special thanks to Professor Q. $\mathrm{Hu}$ of the School of Natural Resources, University of Nebraska, Lincoln, for his comments on the paper.

\section{LITERATURE CITED}

Chen L, Zhu W, Wang W, Zhou X, Li W (1998) Studies on climate change in China in recent 45 years. Acta Meteorol Sin 56:257-271

Chen F, Yu Z, Yang M, Ito E and others (2008) Holocene moisture evolution in arid central Asia and its out-of-phase relationship with Asian monsoon history. Quat Sci Rev 27: 351-364

Chen F, Wang J, Jin L, Zhang Q, Li J, Chen J (2009) Rapid warming in mid-latitude central Asia for the past 100 years. Front Earth Sci China 3:42-50

Ci L (1994) The impact of global change on desertification in China. J Nat Resour 9:289-303

Esper J, Shiyatov SG, Mazepa VS, Wilson RJS, Graybill DA, Funkhouser G (2003) Temperature-sensitive Tien Shan tree ring chronologies show multi-centennial growth trends. Clim Dyn 21:699-706

Fu Z (2001) The cause of E601 evaporation pan greater than that of small type evaporation pan. Meteorol Mon 27: $55-57$

Fu C, An Z (2002) Study of aridification in northern China: a global change issue facing directly the demand of nation. Earth Sci Front 9:271-275

Fu C, An Z, Guo W (2005) Evolution of life-supporting environment in our nation and the predictive study of aridification in northern China. I. Main scientific issues and achievements. Adv Earth Sci 20:1157-1167

Hansen J, Ruedy R, Glascoe J, Sato M (1999) GISS analysis of surface temperature change. J Geophys Res 104: 30997-31022

Hansen J, Ruedy R, Sato M, Lo K (2002) Global warming continues. Science 295:275-276

Huang J (1998) REOF analysis and its application in weather analysis. Meteorology 14:47-51

Hulme M (1996) Recent climate change in the world's drylands. Geophys Res Lett 23:61-64

IPCC (2000) Special report on emissions scenarios. Nakicenovic N, Swart R (eds) Cambridge University Press, Cambridge

IPCC (2007) Climate change 2007: synthesis report. Contribution of Working Groups I, II and III to the fourth assessment report of the Intergovernmental Panel on Climate Change. Core Writing Team, Pachuari RK, Reisinger A (eds) IPCC, Geneva, p 26-73

Jacoby GC, D'Arrigo RD, Davaajamts T (1996) Mongolian tree rings and 20th-century warming. Science 273:771-773

Jiang Z, Ding Y (1998) Generality and applied features for singular spectrum analysis. Acta Meteorol Sin 56:737-744

Jones PD, Moberg A (2003) Hemispheric and large-scale surface air temperature variations: an extensive revision and an update to 2001. J Clim 16:206-223

Kawamura R (1994) A rotated EOF analysis of global sea-surface temperature variability with interannual and interdecadal scales. J Phys Oceanogr 24:707-715

Ma Z, Huang G, Gan W, Chen M (2005) Multi-scale temporal characteristics of the dryness/wetness over Northern China during the last century. Chin J Atmos Sci 29: 671-681 
Mann M, Jones PD (2003) Global surface temperatures over the past two millennia. Geophys Res Lett 30:1820-1824

McKee TB, Doesken NJ, Kleist J (1993) The relationship of drought frequency and duration to time scale. Proc Eighth Conf Appl Climatol, 17-22 Jan 1993. American Meteorological Society, Boston, MA, p 179-184

Palmer WC (1965) Meteorological drought. Research Paper 45, US Department of Commerce, Washington, DC

Palmer WC (1968) Keeping track of crop moisture conditions, nationwide: the new crop moisture index. Weatherwise 21:156-161

Peterson TC, Karl TR, Jamason PF, Knight R, Easterling DR (1998) First difference method: maximizing station density for the calculation of long-term global temperature change. J Geophys Res 103:25967-25974

Ren L, Wang M, Li C, Zhang W (2002) Impacts of human activity on river runoff in the northern area of China. J Hydrol 261:204-217

Servain J, Legler DM (1986) Empirical orthogonal function analyses of tropical Atlantic sea-surface temperature and wind stress: 1964-1979. J Geophys Res 91:14181-14191

Shafer BA, Dezman LE (1982) Development of a Surface Water Supply Index (SWSI) to assess the severity of drought conditions in snowpack runoff areas. Proc Western Snow Conf. Colorado State University, Fort Collins, p 164-175

Shi Y, Shen Y, Li D, Zhang G, Ding Y, Hu R, Kang E (2003) Discussion on the present climate change from warm-dry to warm-wet in Northwest China. Quat Sci 23:152-162

Shi P, Yuan Y, He C, Li X, Chen Y (2004) Land use pattern adjustment under ecological security: look for secure land use pattern in China. Geogr Rev Jpn 77:282-298

Sneyers R (1990) On the statistical analysis of series of obser-

Editorial responsibility: Mauricio Lima, Santiago, Chile vations. Technical Notes 143, World Meteorological Organization, Geneva

Solomon S, Qin D, Manning M, Alley RB and others (2007) Technical summary. In: Solomon S, Qin D, Manning M, Chen Z and others (eds) Climate change 2007: the physical science basis. Contribution of Working Group I to the fourth assessment report of the Intergovernmental Panel on Climate Change. Cambridge University Press, Cambridge

Tao F, Masayuki Y, Yousay H, Lin E (2003) Future climate change, the agricultural water resources, and agricultural production in China. Agric Ecosyst Environ 95: 203-215

Thornthwaite CW (1948) An approach toward a rational classification of climate. Geogr Rev 38:55-94

Tu Q, Deng Z, Zhou X (2000) Regional characteristics of the temperature anomaly in China. Acta Meteorol Sin 58: 288-296

Wang Y (1990) The summary concerning meteorological targets to establish, quote and test in China. Arid Land Geogr 13:80-86

Wang S, Luo Y, Zhao Z, Dong W, Yang B (2005) Disputation about global warming. Prog Nat Sci 15:917-922

Wei F (1999) Climate statistical diagnosis and forecast technology. Meteorological Press, Beijing

Wu H, Duan A (1998) Long-term trend and oscillation detection in Lanzhou temperature and experimental forecasts. J Nanjing Inst Meteorol 21:629-636

Yang L (2003) The climate change of extreme precipitation in Xinjiang. Acta Geogr Sin 58:577-583

Zhang X (1989) The potential evapotranspiration (PE) index for vegetation and vegetation-climatic classification (2): an introduction of main methods and PEP program. Acta Phytoecol Sin 13:197-207

Submitted: November 26, 2008; Accepted: November 16, 2009 Proofs received from author(s): February 6, 2010 